\title{
Retorno crítico à noção de ethos*
}

\author{
Critical retourn to the notion of ethos \\ Dominique Maingueneau \\ Sorbonne Université, Paris, França.
}

$\diamond$

Resumo: Este artigo tem o objetivo de desenvolver uma reflexão crítica sobre o uso que é comumente feito do ethos discursivo, há quinze anos, nos trabalhos de análise do discurso. Essa reflexão é ao mesmo tempo autocrítica, uma vez que, desde a década de 1980, contribuí para o desenvolvimento dessa problemática. Inicialmente, procuro analisar mais precisamente o conteúdo da noção de ethos, em que distingo três dimensões: categorial, experiencial e ideológica. Esta tripartição é necessária se quisermos levar em conta a diversidade de manifestações do discurso. Em um segundo momento, reflito sobre o próprio processo de construção do ethos, baseando-me em dados - particularmente em anúncios de sites de relacionamento - diferentes daqueles que geralmente estudamos quando trabalhamos com o ethos. Finalmente, em um terceiro momento, me interesso pelos problemas levantados pela análise do ethos discursivo quando se trabalha com textos nos quais as dimensões verbal e icônica estão estreitamente ligadas. Dois tipos de fenômenos são considerados: os sites da Internet, nos quais estão implicados ethos verbal e ethos digital, e as publicidades.

Palavras-chave: análise do discurso; ethos; ethos discursivo; incorporação; site de relacionamento.

\begin{abstract}
This article aims at criticizing the way the notion of discursive ethos has been generally used by discourse analysts for about fifteen years. This criticism is at the same time self-criticism, because from the 1980's on I contributed to develop this field of research. Firstly, I try to analyze the content of the notion of ethos, which I divide into three dimensions: "categorial", "experiential", "ideological". Such a division allows us to take into account the full diversity of activity. Secondly, I reflect on the very process through which addressees construct ethos; this reflection draws on data from matchmaking websites, not from the kind of corpora (political discourse, advertising, literature...) that are usually analyzed by the researchers who work on ethos. Thirdly, this article deals with the problems that one encounters when one studies texts in which iconic and verbal dimensions are tightly connected. Two kinds of data are taken into consideration: websites, which imply both digital and verbal ethos, and commercials.
\end{abstract}

Keywords: discourse analysis; ethos; discursive ethos; incorporation; matchmaking website.

\footnotetext{
* Tradução do francês de Maria da Glória Corrêa di Fanti (gloria.difanti@pucrs.br - https://orcid.org/0000-0002-5399-5377 - PUCRS/CNPq) e Liz Feré (info@lizfere.com - https://orcid.org/0000-0001-9210-4568 - Centre d'Études sur les Médias, les Technologies et l'Internalisation (CEMTI), Université Paris VIII), com revisão do autor. Este artigo foi publicado originalmente sob o título "Retour critique sur l'éthos" na revista Langage et Société, 2014, v. 149, n. 3, p. 31-48. [https://www.cairn.info/revue-langage-et-societe-2014-3-page-31.htm]. Uma tradução com o título "Retorno crítico sobre o ethos", realizada por Paula Mesti, foi publicada no livro Análise do Discurso: entorno da problemática do ethos, do político e de discursos constituintes, organizado por Roberto Baronas, Paula Mesti e Renata Carreon, e editado pela Pontes, em 2016.
} 
Apesar de eu fazer parte daqueles que introduziram em análise do discurso a problemática do ethos, mais especificamente de ethos discursivo (MAINGUENEAU, 1984, 2002; AMOSSY, 1999), tenho consciência de que sua investigação levanta múltiplas dificuldades, algumas das quais foram evidenciadas. ${ }^{1}$ Até o momento, o ethos é um termo muito pouco especificado se quisermos apreender eficazmente os enunciados em toda sua diversidade.

Em um primeiro momento, esforçar-me-ei em propor uma análise mais precisa da noção de ethos; minha reflexão focará em seguida a relação entre ethos dito e ethos mostrado e a complexidade das estratégias que devem mobilizar os destinatários para atribuir um ethos ao enunciador. Para finalizar, insistirei sobre diversos problemas que o analista do discurso encontra quando confrontado com corpora que não são constituídos de materiais estritamente verbais.

\section{As três dimensões do ethos}

Algo que chama particularmente a atenção quando percorremos os trabalhos que fazem uso do ethos é que seu conteúdo é muito variável, ou até controverso. Por exemplo, fala-se de ethos "de professor", "de esposa", "de político", "de competência"..., de ethos "calma", "comunista", "rural", "profético" etc. Isso compreende: o conteúdo que é dado ao ethos depende consideravelmente dos tipos ou gêneros de discurso que se estuda de maneira privilegiada; examina-se raramente o discurso em toda sua diversidade.

A esse respeito, eu não estou isento de críticas. Minha própria concepção de ethos foi sem dúvida marcada pelo fato que coloquei à prova sobretudo textos religiosos, publicitários ou literários: o destinatário constrói a figura de um fiador dotado de propriedades físicas (corporalidade) e psicológicas (caráter), apoiando-se sobre um conjunto difuso de representações sociais avaliadas positiva ou negativamente, de estereótipos que a enunciação contribui a fortalecer ou a transformar. Uma grande parte do poder de persuasão de um discurso se mantém no fato que ele leva o destinatário a se identificar ao movimento de um corpo, seja ele muito esquematizado, investido de valores historicamente especificados. As "ideias" suscitam a adesão do leitor através de uma maneira de dizer que é também uma maneira de ser. Essa concepção de ethos é colocada em evidência através do conceito de incorporação, que se apresenta em três registros:

- a enunciação confere uma corporalidade ao fiador, ela dá corpo a ele;

\footnotetext{
1 Ver particulamente Auchlin (2001).
}

- o destinatário incorpora, assimila através da enunciação um conjunto de esquemas que correspondem a uma maneira específica de se relacionar com o mundo;

- essas duas primeiras incorporações permitem a constituição de um corpo da comunidade imaginária daqueles que aderem ao mesmo discurso.

Essa incorporação do destinatário implica um mundo ético (MAINGUENEAU, 2000) do qual o fiador participa. Esse mundo ético inclui um certo número de situações estereotipadas associadas a comportamentos verbais e não verbais (o mundo ético do quadro dinâmico, esnobes, estrelas de cinema etc.).

O problema é que esse conceito de ethos não permite a análise com a mesma eficácia para todos os tipos de textos. É por isso que eu proponho, com o presente trabalho, atribuir ao ethos três dimensões (categorial, experiencial e ideológica) que são mais ou menos marcantes segundo os textos que são considerados:

1. a dimensão "categorial" recobre coisas muito diversas. Ela pode tratar de papéis discursivos ou de status extradiscursivos. Os papéis discursivos são aqueles ligados à atividade de palavra: animador, contador, pregador... Os status extradiscursivos podem ser de natureza muito variada: pai de família, funcionário, médico, camponês, americano, solteiro etc.;

2. a dimensão "experiencial" do ethos recobre as características sócio-psicológicas estereotipadas, associadas às noções de incorporação e de mundo ético: bom senso e lentidão do camponês, dinâmica do jovem empreendedor...;

3. a dimensão "ideológica" refere-se a posicionamentos dentro de um campo: feminista, de esquerda, conservador ou anticlerical... dentro do campo político, romântico ou naturalista... dentro do campo literário etc.

Essas três dimensões interagem fortemente. O camponês (categorial) tem afinidades estereotipadas com o bom senso (experiencial) e o conservadorismo (ideológico); o cabeleireiro ou o criador de moda (categorial) fazem alusão a um comportamento efeminado (experiencial) etc.

A priori, a lista dos predicados que se pode levar em conta para caracterizar um ethos está aberta. Mas, sem dizê-la explicitamente, a maioria das vezes os analistas filtram de maneira drástica os elementos que eles julgam pertinentes em função do gênero e do tipo de discurso. Quando se trata de estudar anúncios de sites de relacionamento, são privilegiados inevitavelmente os predicados de ordem psicológica ou comportamental 
(culto, esportivo, simples...) colocando-os em relação com o status: parisiense, solteiro, aposentado... Por outro lado, quando se trata do gênero político eleitoral, o analista vai privilegiar primeiramente os predicados que dizem respeito ao posicionamento ideológico (de direita, pro-europeu, anarquista...) e os predicados psicológicos pertinentes (competência, autoridade, honestidade, coragem...).

\section{Problemas de estratégia interpretativa}

\subsection{Algumas distinções}

A maior parte dos trabalhos sobre ethos é como se sua identificação estivesse evidente. Isto é sem dúvida ligado aos tipos de corpus que são os mais estudados: publicitários, literários, científicos, políticos... Trata-se aí de textos escritos por profissionais que conhecem as técnicas de expressão e de quem as produções podem facilmente se analisar em termos de estratégias e de objetivos claramente identificáveis, visto que são fortemente dependentes da situação de comunicação. Para estudar textos desse tipo, podemos nos apoiar sobre um certo número de pontos de referência que vão, de alguma forma, colocar em simetria a relação entre o produtor do discurso e seu intérprete: o ethos participa de uma estratégia coerente, destinada a resolver um problema facilmente identificável. Mas é preciso sair desses corpora privilegiados para perceber que a construção do ethos é muito frequentemente uma tarefa incerta: porque os locutores ou os intérpretes não são experts, ou simplesmente porque os gêneros ou os tipos de discurso em questão não oferecem condições favoráveis.

É o que vamos poder verificar em um exemplo que foi tirado da Internet, mais precisamente em sites de relacionamento, cuja função é colocar em relação indivíduos que procuram um parceiro amoroso. Certos sites solicitam aos seus membros a redação de um curto texto de apresentação pessoal. Esse material é particularmente interessante para refletir sobre o ethos discursivo, visto que se trata de um gênero de discurso (a exemplo de outros como o $\mathrm{CV}$ ou as sessões de psicoterapia) em que o locutor é obrigado a falar de si e o destinatário obrigado a atribuir um ethos ao locutor para tomar uma decisão favorável ou desfavorável: nesse caso contactar alguém em vista de um possível relacionamento amoroso, contratar um colaborador, fazer um diagnóstico psicopatológico. No entanto, esses anúncios em sites de relacionamento, embora sejam textos monologais particularmente bem controlados, o processo de atribuição de um ethos a seu locutor não é nada evidente. Veremos, comentando alguns exem- plos coletados ${ }^{2}$ no site líder desse mercado, o Meetic (www.meetic.fr).

Antes de comentar sobre esses exemplos, é necessário mencionar rapidamente a distinção sobre a qual nós vamos nos apoiar: entre ethos dito (o que o locutor diz sobre si mesmo) e ethos mostrado (o que mostra sua maneira de enunciar).

Em muitas análises do ethos, os índices são coletados tanto no ethos dito quanto no ethos mostrado, ou em apenas um dos dois, sem que essa distinção seja apresentada. Essa distinção é expressa por Ducrot (1984, p.201) através da oposição entre locutor- $L$ e locutor- $\lambda$. O locutor- $L$ (o locutor enquanto ele está enunciando) é suposto promover as qualidades do locutor- $\lambda$ (o locutor como um ser do mundo, fora da enunciação). Essa distinção é semelhante à dos pragmatistas entre mostrar e dizer: o ethos discursivo mostra-se no ato de enunciação, não é dito no enunciado. Por um lado, há "a comunicação de um conteúdo", por outro "a comunicação pelo fato de que sua comunicação foi feita de certo modo" (RECANATI, 1981, p. 47). O ethos discursivo é, portanto, percebido, mas não é o objeto do discurso.

Enquanto o ethos discursivo é parte integrante de toda enunciação, o ethos dito não é obrigatório. Ducrot evoca apenas o ethos dito relativo à personalidade do locutor; mas pode-se argumentar que há também um ethos dito verbal, isto é, que se relaciona com as propriedades da própria enunciação ("minha palavra é severa", "eu falo com você do fundo do coração “...). Em muitos casos, esse retorno do enunciado sobre a enunciação desempenha um papel importante.

Os analistas do discurso, além disso, distinguem "ethos prévio" (ou "pré-discursivo") e "ethos discursivo", observando que os destinatários geralmente têm uma representação do locutor anterior a seu discurso. Isso é particularmente evidente para aqueles que ocupam a cena midiática. No caso de anúncios de sites de relacionamento, no entanto, não se espera que os destinatários conheçam previamente a identidade do ou da anunciante. O ethos dito de natureza não verbal, que trata da personalidade do locutor, ocupa aí naturalmente um lugar importante. O locutor dá informações sobre si mesmo que o leitor pode confrontar com o ethos discursivo do anúncio. Essas informações são essencialmente de dois tipos: de ordem social (local de residência, estado civil, profissão...) e especialmente de ordem psicológica (caráter, gostos...): "Eu sou um homem meigo", "Eu gosto de festejar com os amigos"...

\footnotetext{
2 Nos dias 10/3/2008, 16/8/2010 e 17/9/2009. Na medida em que os anunciantes podem alterar os anúncios a qualquer momento e podem se inscrever em um tempo muito variável, não há nenhum vestígio disso alguns anos depois. $\mathrm{O}$ site não fornece nenhuma instrução para escrever o anúncio; a única restrição explícita é formal: "O texto do anúncio deve ter no mínimo 50 caracteres e no máximo 2.000 ”.
} 
A leitura do corpus permite discernir três estratégias principais no gerenciamento da relação entre ethos dito e ethos mostrado. A primeira consiste em instituir uma ruptura entre eles por meio do apagamento do ethos mostrado; a segunda consiste em produzir uma convergência, isto é, apoiar o ethos dito pelo ethos mostrado e estabilizar o ethos mostrado usando o ethos dito. A terceira estratégia, mais rara, consiste em fazer desaparecer o ethos dito em favor do único ethos mostrado.

\subsection{O apagamento do ethos mostrado}

Esse anúncio muito curto foi escrito por uma mulher que usou o pseudônimo "Nana":3

Eu tenho 35 anos morena com olhos azuis com formas generosas, gosto de viajar e todas as coisas boas da vida. Desejo conhecer alguém atencioso e generoso, sorridente como eu sou... Até breve.

O texto contém elementos que remetem ao ethos dito; eles fornecem informações sobre o físico e moral da anunciante. A ruptura modal estabelecida entre esse ethos dito e o ethos mostrado faz com que o leitor não perceba em que as características dessa enunciação mostram uma locutora que gosta de "as coisas boas da vida" em vez de uma esportista, sonhadora ou caprichosa. Nesse texto, o "eu" poderia então ser facilmente substituído por uma não pessoa, de acordo com o modelo do pequeno anúncio tradicional: "mulher, 35 anos, morena..."

O mesmo vale para esse anúncio publicado por um homem cujo pseudônimo é "Ezechiel”:

Eu sou um homem de 56 anos, moreno com olhos castanhos, magro. Separado há vários meses e pai de dois filhos. Sou responsável pela publicação em uma editora universitária em Paris.

Eu sou de origem catalã. Sincero, autêntico, tenho o gosto pelos outros. Estou engajado em ação humanitária, adoro viajar... Homem de caráter um tanto frágil, sensível e romântico, espero de uma mulher: inteligência, sensibilidade, uma boa dose de humor, e ternura para compartilhar bons momentos a dois... Estou esperando por você.

Para esse tipo de anúncio, como exemplificado por Nana e Ezechiel, poderíamos falar de um apagamento do ethos, como falamos de um apagamento enunciativo (VION, 2001; RABATEL, 2004) para designar a estratégia que consiste para o locutor em dar a impressão "de

\footnotetext{
3 Os anúncios são transcritos como foram publicados, com seus possíveis erros de ortografia e digitação. É de fato essencial dispor do texto como é oferecido à avaliação dos destinatários.
}

que ele se retira da enunciação", que ele "objetiviza" seu discurso "apagando" não apenas as marcas mais óbvias de sua presença (os embreantes), mas também a marcação de qualquer fonte enunciativa identificável (VION, 2001, p.334). Essa estratégia enunciativa é particularmente visível na enunciação histórica, tal como descrita por Benveniste, ou em textos teóricos, em que os eventos ou argumentos são apresentados como independente de qualquer intervenção do sujeito falante. Mas essa encenação está sempre ameaçada pelo retorno da subjetividade enunciativa.

\subsection{A convergência entre ethos dito e mostrado}

Quando há convergência entre ethos dito e mostrado, existe um apoio mútuo entre eles. Eis um exemplo:

Erminat, 51 anos:

Eu gosto da espiritualidade, da responsabilidade e da tenacidade. Esses três valores naturalmente implicam uma busca refinada e elitista do ideal masculino. Isso só pode ser para homens de coragem que assumem responsabilidades importantes, mantendo o controle sobre suas situações. Isso requer classe, mas também respeito aos outros. Para dizer a verdade, não são numerosos os que possuem tais qualidades.

Terei prazer de ler sua resposta.

O ethos assim mostrado aparece como sintomático da personalidade da locutora; o leitor pode realmente pensar que essa mulher fala do modo que ela diz que é: clara, direta.

\subsection{O desaparecimento do ethos dito}

No anúncio seguinte, é o ethos dito que desaparece, pelo menos de uma forma direta. $\mathrm{O}$ ethos da anunciante que podemos construir é, portanto, baseado em um único ethos mostrado.
VIEDEDEN, 36 anos:
Imponha sua sorte, Abrace sua felicidade,
\& vá em direção ao seu risco.
Ao olhar para você,
Eles vão se acostumar...
VOCÊ...
Me mostre suas mãos...
EU...
As mulheres nunca são mais fortes do que quando se armam com a sua fraqueza...

A anunciante utiliza uma cenografia ostensivamente literária, que, além disso, mobiliza uma relação 
hipotextual. Ela incorporou, de fato, e transformou em verso um fragmento de prosa poética publicada por René Char: "Imponha sua sorte, abrace sua felicidade e vá em direção ao seu risco. Ao olhar para você, eles vão se acostumar com isso". ${ }^{4}$ Tal anúncio, é claro, viola abertamente as expectativas do leitor, mas esse último é levado a aplicar as máximas conversacionais de Grice, fazendo a hipótese de que a transgressão aparente das restrições do gênero (se descrever) é na verdade uma forma indireta de respeitá-las. É suficiente para o leitor postular que o locutor conhece as regras do jogo e presume que seus destinatários as conheçam para desencadear uma atividade inferencial, o que permitirá atribuir ao fiador desse texto um ethos apropriado. Esse ethos pode ser construído em três níveis: a) o da metaenunciação: a anunciante é essa mulher (original, não conformista, inacessível...) que é capaz de escrever tal texto, b) o da enunciação: sua personalidade é revelada através do seu ethos discursivo ("sonhadora", "amorosa", "poeta"...), c) o do enunciado: uma certa forma de entender a relação entre o homem e eu é tematizada nesse texto que trata da relação amorosa. Mas essa cenografia também define, obliquamente, as características do destinatário ideal: deve ser um homem capaz de construir o ethos da mulher que é capaz de tal enunciação.

De um ponto de vista quantitativo, os anúncios que apagam o ethos dito em favor do ethos mostrado só podem ser marginais. De fato, para a busca de um parceiro, a ausência de ethos dito significa correr grandes riscos: como um ethos puramente mostrado é dificilmente interpretável, o anúncio só pode ser destinado para um número muito limitado de leitores, prontos a assumir o alto custo cognitivo da interpretação em um espaço onde a concorrência é forte.

\section{Problemas de construção do ethos}

A distinção entre essas três estratégias (ruptura ou convergência entre o ethos dito e o ethos mostrado ou desaparecimento do ethos dito) parece satisfatória, desde que não consideremos os problemas que devem enfrentar concretamente os intérpretes desses anúncios que, para tomar uma decisão, são obrigados a atribuir um ethos ao locutor.

Consideraremos primeiro o apagamento do ethos. Nesse caso, o destinatário não deve considerar o ethos discursivo, mas focalizar sua atenção unicamente no ethos dito. Mas como o leitor pode ter certeza de que se trata de um apagamento de ethos? Como toda enunciação provoca inevitavelmente uma construção de ethos, muitos leitores tenderão a interpretar como a manifestação de um

\footnotetext{
4 Les Matinaux, Gallimard, 1950; reedição 1984: 75.
}

ethos especificado o que acabamos de caracterizar como um apagamento de ethos. Eles serão capazes de produzir no anunciante ou na anunciante avaliações positivas (por exemplo, em termos de seriedade, confiabilidade, competência...) ou negativas (banalidade, frieza, timidez...).

Podemos ir mais longe. Não se sabe ao certo se essa impressão de apagamento é o resultado de uma estratégia deliberada; não é o produto da incapacidade do anunciante de lidar facilmente com a língua? Ele ou ela esconder-se-ia atrás de um código impessoal para contornar a dificuldade.

No exemplo da convergência entre dito e mostrado prototípico que citamos (o anúncio de "Erminat"), lemos um ethos mostrado sintomático da personalidade da anunciante. $\mathrm{Na}$ realidade, é uma decisão interpretativa do leitor determinar se o ethos mostrado é um sintoma ou uma estratégia. Interpretá-lo como um sintoma é considerar que a maneira de dizer do locutor exprime diretamente sua personalidade. Interpretá-lo como estratégia é atribuir ao locutor uma escolha retórica entre um conjunto de opções. Conforme se decide por uma ou outra interpretação, as consequências em termos de avaliação da personalidade são diferentes. Vê-se nisso uma estratégia consciente; poder-se-á considerar, por exemplo, que o ethos exibido pela anunciante é destinado a desviar os importunos que ela "adiciona". Mesmo que adote a primeira solução, a do sintoma, a interpretação do ethos não é tão fácil quanto parece. Nada permite decidir entre avaliação positiva (uma mulher franca, corajosa, exigente...) e negativa (enfadonha, tirânica, brutal...).

Também pode acontecer que o ethos dito e o ethos mostrado sejam divergentes, por exemplo, se um ethos mostrado didático e meticuloso estivesse associado a um ethos dito que apresentasse o caráter fantasioso do locutor. Mas pode-se também interpretar essa divergência como uma enunciação irônica em vez de decidir que se trata de uma contradição. Pior: a contradição só pode existir na mente do intérprete: o locutor não é obrigado a dizer de maneira fantasiosa que ele é fantasioso e pode ter optado por um apagamento do ethos. Se esse for o caso, trata-se de timidez? Uma relutância em escrever um anúncio? Um desejo deliberado de se revelar apenas em um momento posterior?

Até mesmo o anúncio muito literário de VIEDEDEN provavelmente não é tão unívoco quanto se poderia pensar. A análise do ethos que propusemos baseia-se em um processo semelhante ao das máximas conversacionais de Grice, que permite atribuir, mesmo assim, um ethos à anunciante. Mas isso não impede que o destinatário veja uma mulher complicada, afastada da realidade, narcisista etc., ou seja, que não se atenha ao que o texto pretende impor-lhe. Nós podemos levar a dúvida mais adiante. A 
maioria dos textos não é produzida por especialistas em comunicação verbal, e esses dados massivos raramente são levados em consideração pelos analistas, que, como dissemos, trabalham com um corpus em que não emerge essa questão. Consideremos, como ilustração, o seguinte anúncio:

\section{Bill, 42 anos:}

estou a procura de uma mulher que tem os olho verde os cabelos castanho

Este anúncio, como o de VIEDEDEN, transgride abertamente as normas do intercâmbio; ele propõe um enunciado minimalista que pareceria perfeitamente literário se a ortografia não fosse tão ostensivamente falha. ${ }^{5}$ Para a maioria dos leitores que possuem um bom domínio da ortografia, esses erros provavelmente são suficientes para bloquear uma interpretação que depende de um mecanismo segundo Grice. Que ethos atribuir a um enunciador que se acredita ter um domínio insuficiente da comunicação verbal?

Como se vê, antes de atribuir um ethos ao locutor, devemos passar o enunciado por um primeiro filtro, de natureza metadiscursiva, que consiste em fazer um diagnóstico de suas competências linguageiras. Além disso, as transgressões da norma podem ser interpretadas pelo destinatário de formas muito variadas: uma língua estrangeira mal dominada, uma falta de competência comunicativa (a da escrita ou do gênero de discurso), um estado de saúde que faz o locutor perder suas capacidades (ou seus meios)...

No anúncio a seguir, vemos as dificuldades se acumularem:

\footnotetext{
Waoite (54 anos):

sou um homem quieto, calmo, reservado, meigo, adoro a tranquilidade, o mar e sobretudo a natureza. eu gosto de ir ao cinema, a leitura, os eventos esprotivos. Cozinhar e passear de bicicleta, também as viagens. eu vou uma vez por anos.
}

Trata-se de um apagamento de ethos? Uma convergência entre ethos dito e mostrado (o caráter "calmo, reservado, meigo" do locutor se manifestaria através de um ethos discursivo sem ênfase)? Mas também é possível, tendo em vista a ortografia defeituosa e a sintaxe paratática, considerar que o locutor não domina a expressão o suficiente para que o ethos seja interpretável: é então um ethos não visado pelo locutor que prevalecerá, o de um homem pouco instruído, incapaz de se

\footnotetext{
5 NT: O anúncio original apresenta problemas de ortografia e de concordância. As palavras "yeux" (olhos) e "cheveux" (cabelos) são grafadas como "yeus" e "cheveus". A palavra "vert" (verde) deveria estar no plural para concordar com "yeux".
}

expressar. ${ }^{6}$ Além disso, não se deve esquecer que a percepção e a avaliação dos erros de expressão dependem do grau de instrução da leitora e da importância que ela atribui ao domínio da palavra escrita. Não se pode excluir totalmente que, para algumas leitoras, a pobreza dos meios de expressão autentica o espírito discursivo de um homem que afirma sua simplicidade, apesar dos erros de ortografia. Em sua tipologia dos ethé, Aristóteles também menciona um tipo de ethos, que ele chama aretê, o do orador que persuade pelo próprio fato de que sua enunciação é percebida como bruta, sem correções, sincera. O problema é que Aristóteles considera essa possibilidade no âmbito de uma competência de especialistas, não em situações da vida cotidiana.

À luz de tais exemplos, vê-se como é difícil comparar o apagamento de ethos com a simples não incompatibilidade entre ethos dito e ethos mostrado. Sobre esse ponto, é interessante comparar o apagamento de ethos dos nossos anúncios com outro gênero de apresentação de si.

O Jardim Botânico do Bronx, em Nova York, durante o inverno de 2012, recrutou meninas (categorizadas como explainers) para explicar às crianças certas propriedades dos vegetais. Em uma das paredes da sala onde elas atuavam, estavam justapostos, ao lado da foto de seus rostos, textos curtos em que elas se apresentavam ao público.

Aqui estão dois exemplos, o primeiro atribuído a uma garota branca (Ilaria), o outro a uma moça negra (Keishanna). Se considerarmos o ethos dito, a divergência é considerável entre os dois textos. É claro que as duas meninas não pertencem ao mesmo meio social e não dispõem do mesmo capital cultural.

Meu nome é Ilaria Lampson e sou estudante da Pelham Memorial High School. Eu me candidatei para o programa teen explainer em 2012 porque eu amo o ambiente do jardim e gosto de estar cercada por sua beleza. Ser uma explainer é incrível e eu conheci tantas pessoas maravilhosas de toda Nova York e seus bairros. O Everett Children's Garden é muito dedicado a ensinar as crianças pequenas e suas famílias sobre a natureza. Isso me fez acreditar que eu era perfeita para o programa. Nos meus dias de semana, eu me envolvo em atividades como patinação artística, ser parte do modelo das Nações Unidas, praticar balé e frequentar aulas de idiomas adicionais. Acho a ciência muito interessante e espero aprender mais sobre o ciclo de vida de uma planta e como elas sobrevivem na natureza.?

\footnotetext{
6 NT: O anúncio original apresenta diferentes problemas, como de ortografia ("sprotifs" por "sportifs" e "part" por "pars"), de acentuação ("evenements" por "événements") e concordância ("ans" por "an").

7 NT: Texto original: My name is Ilaria Lampson and I am a student at Pelham Memorial High School. I applied for the teen explainer program in 2012 because I love the environment of the garden and I enjoy being surrounded by its beauty. Being an explainer is amazing and I have met so many great people from all over New York and its boroughs. The
} 
Olá, meu nome é Keishanna Bernard, mas as pessoas me chamam de Kish. Atualmente frequento a escola no Christopher Colombus Campus, mas minha escola original é o Collegiate Institute for Matth and Science. Eu me tornei um explainer em outono de 2012. Meus hobbies favoritos são jogar videogames, dormir e comer. Quatro anos atrás, eu era uma participante ativa em atletismo. Meus temas favoritos são ambiente e inglês. Algumas coisas interessantes sobre mim são que eu também rio muito. Meu objetivo na vida é duplicar a importância da biologia marinha e da enfermagem. ${ }^{8}$

Nesses textos, o ethos dito é saliente. O ethos mostrado, relegado a segundo plano, não é realmente específico para cada um. Tudo o que se pode dizer sobre isso é que não é incompatível com o ethos dito. $\mathrm{O}$ visitante, contudo, percebe uma clara diferença de elaboração entre os dois textos, especialmente no que diz respeito à manipulação da linguagem escrita, diferença acentuada no imaginário do leitor pelo ethos dito. Mas também se pode questionar se não há para a jovem negra uma recusa em levar a sério esse gênero de texto, como mostra a marginalização de seu nome oficial em relação ao seu apelido ou a categorização de "comer e dormir" como "hobbies"; nesse caso, um certo ethos discursivo apareceria de qualquer forma.

O caráter muito restrito da formatação, tanto para a extensão quanto para o conteúdo (a redação do texto deve claramente seguir normas precisas: identidade, motivação, passatempos, projetos), e a provável intervenção de um intermediário autorizado pela instituição para ler os textos contribuem para reduzir essa divergência. Como em uma sobreposição de impressões fotográficas, duas instâncias enunciativas se misturam: a instituição e o indivíduo em sua singularidade. Este é, sem dúvida, o efeito desejado: dar a sensação de diversidade, mantendo a unidade imaginária de uma comunidade unida, servindo ao mesmo propósito. Em vez de um apagamento do ethos, parece que estamos lidando com uma relativa neutralização do ethos mostrado, de acordo com os interesses da instituição.

Everett Children's Garden is very devoted to teaching small children and their families all about nature. This made me believe I was a perfect fit for the program. On my weekdays, I involve myself in activities including figure skating, being part of the model United Nations, practicing ballet, and attending additional language classes. I find science very interesting and hope to learn more about the life cycle of a plant, and how they survive in nature.

8 NT: Texto original: Hi, my name is Keishanna Bernard, but people call me Kish for short. I currently attend school at Christopher Colombus Campus, but my original school is Collegiate institute for math and science. I became an explainer in the fall of 2012. My favorite hobbies are playing video games, sleeping and eating. Four years ago, I was an active participant in track and field. My favorite subjects are living environment and English. Some interesting things about me are that I laugh a lot, too. My goal in life is to double major in marine biology and nursing.
No exemplo anterior, podemos invocar a necessidade de a instituição suavizar as diferenças entre as meninas. Esse não é o caso da entrevista dada por Anne Hidalgo, vice-prefeita, que pretende mostrar que ela tem as qualidades necessárias para ser a próxima prefeita de Paris:

\begin{abstract}
Não acho que minha proximidade com o atual prefeito de Paris seja uma desvantagem. Assim, eu me beneficio de uma experiência e de um balanço, que eu assumo, e que é positivo. E, além disso, os Parisienses apreciam que não haja divisão do nosso lado, ao contrário do que acontece com a direita [...] Os Parisienses não esperam pelo homem ou pela mulher providencial e não adianta chegar com uma foto de "esnobe-bobo" para ser "parisiense-compatível". É preciso provar com ações para seduzi-los. E o que estão procurando pessoas como Borloo ou Fillon? Um trampolim para a eleição presidencial de 2017? Não estou convencida de que isso agrade aos Parisienses. (20 minutos, 09/01/2013, p. 2).
\end{abstract}

Aqui também as características do ethos dito passam para o primeiro plano: o texto descreve as qualidades da locutora. O ethos mostrado, por outro lado, é pouco especificado: ele se contenta em não ser incompatível com o ethos dito. Isto leva a uma gradação: apagamento de ethos mostrado > não incompatibilidade entre ethos dito e mostrado $>$ convergência/divergência entre ethos dito e mostrado.

Esse exemplo também mostra que o ethos não pode ser construído sobre um único nível. Se tomarmos nossa divisão tripartite da cena da enunciação em - cena englobante, cena genérica e cenografia (MAINGUENEAU, 1998) -, pode-se dizer que o ethos é imposto por esses três níveis, e não apenas pela cenografia, isto é, pela encenação singular que a enunciação instaura. Em relação à cena englobante (aqui o discurso político), a norma dominante para alguém que pertence a um "partido do governo" é mostrar qualidades como seriedade, honestidade, amor por seu país, dedicação, senso de responsabilidade etc. No nível do gênero entrevista com um jornalista, também estão envolvidas limitações específicas: falar de forma simples, ser claro, cortês etc.

Como podemos ver, o recurso ao ethos para analisar enunciados muito restritos, produzidos por interlocutores especializados, não deve fazer esquecer a complexidade e a incerteza fundamental dos processos interpretativos na maioria das situações de comunicação. Em muitos casos, não podemos postular o ethos como uma evidência sobre a qual nos basearíamos para, em seguida, nos perguntar por que esse ethos é mais do que um outro que foi escolhido pelo locutor. É necessário assumir o fato de que o ethos tem um duplo status: ele é tanto visado 
pelo locutor quanto construído pelos destinatários, que precisam fazer hipóteses sobre as intenções do locutor. Esses destinatários procedem de acordo com os recursos linguísticos e culturais de que dispõem e de acordo com seus interesses na interação. No caso de anúncios em um site de relacionamento, os leitores inevitavelmente tendem a impulsionar os cálculos interpretativos, já que o resultado desses cálculos leva a uma tomada de decisão que pode ter consequências pesadas para eles.

\section{Ethos, texto e imagem}

Na seção anterior, com base em textos publicados em um site de relacionamento, refletimos sobre alguns dos problemas que a interpretação do ethos coloca. Mas nós não levamos em conta o fato de que se tratava de um site da Internet. Não podemos ignorar, no entanto, que esses anúncios também são um componente desse conjunto maior que é o perfil do membro, ele mesmo incluído em um site que associa estreitamente elementos verbais e icônicos. O ethos de cada locutor é assim dominado pelo ethos atribuído a esse metaenunciador que é a marca responsável pelo site, nesse caso, pelo nosso corpus, Meetic. No entanto, deve-se reconhecer que os trabalhos que mobilizam a noção de ethos têm pouco interesse nos ethé hierarquizados que interagem em uma enunciação (por exemplo, entre um jornal e os vários artigos que ele contém, ou entre um programa de televisão e os locutores que se expressam em seu quadro) e os ethé que resultam da multimodalidade, especialmente quando há uma combinação de textos e imagens.

\subsection{Ethos e cenografia digital}

Essas limitações são particularmente evidentes quando abordamos a Internet, cujo funcionamento não decorre da concepção clássica do gênero, que serve como base implícita para a maioria dos trabalhos sobre o ethos. Nesse dispositivo que chamamos de "clássico", o gênero de discurso é estruturado em vários níveis: tipo de discurso $>$ gênero de discurso > situação de enunciação singular; isso que expressamos com o auxílio da tripartição: cena englobante $>$ cena genérica $>$ cenografia. A cena genérica desempenha o papel de pivô e o hipergênero um papel periférico. Na Internet a situação é muito diferente. As restrições impostas pela cena genérica são de fato fracas. As unidades de comunicação, a saber os sites, são de fato da mesma natureza e estão sujeitas a um conjunto de restrições de caráter técnico; essa homogeneização é reforçada pela necessidade de poder circular por hiperlinks de um site para outro. Sendo assim, na Internet, a cenografia e o hipergênero desempenham o papel essencial. A cenografia, porque o principal problema é encenar a comunicação, mobilizando massivamente os recursos verbais e multimodais propriamente ditos (imagem parada, movimento, som) e operações hipertextuais. O hipergênero, porque os sites são divididos em categorias amplas, como "sites comerciais", "blogs", "sites de informação" etc., com formatos pouco restritos que possibilitam cenografias muito variadas.

Mais precisamente, a cenografia da Internet é dupla: verbal e digital. A cenografia "verbal" é aquela que a enunciação propriamente linguística implica. Quanto à cenografia "digital", ela comporta três dimensões:

- iconotexual: o site mostra imagens e constitui um conjunto de imagens em uma tela;

- arquitetural: o site é uma rede de páginas organizadas de uma determinada maneira;

- procedural: cada site é uma rede de instruções.

Essas três dimensões podem convergir ou divergir: por exemplo, uma cenografia procedural muito didática pode entrar em contradição com uma cenografia iconotextual muito poética (cores pastel, tipografia elegante...).

$\mathrm{O}$ enfraquecimento da cena genérica na Internet também se manifesta através da fragmentação das páginas da tela: não é o caso de um texto, mas de um mosaico de módulos heterogêneos, o que torna impossível a correspondência simples de um texto com uma cena de enunciação. É de fato uma tela que se oferece ao olhar, isto é, uma visão parcial de uma totalidade que nunca se dá completamente. Há, portanto, uma divergência essencial entre a "paginação" da Internet e uma página impressa. Além disso, a heterogeneidade enunciativa entre módulos é patente: encontram-se listas de vários tipos, diagramas, publicidades, início de artigos, slogans, manchetes, instruções etc. Esses próprios módulos obedecem a temporalidades distintas: o que aparece na tela é apenas um estado transitório, cuja maioria dos constituintes é renovada.

Essas poucas características convergem para minar o regime clássico da textualidade e o tipo de genericidade que lhe é solidário. Isso não deixa de ter uma incidência sobre o ethos. Duas consequências aparecem como evidentes:

1. a relação entre o ethos de cada módulo e o ethos do site é muito variável: existem módulos-textos com um ethos consistente relativamente autônomo e módulos que são diretamente a projeção do ethos do site (como os títulos, as listas de notícias...);

2. o ethos propriamente verbal perde sua importância em favor de um ethos global, muito mais vago, que excede as caracterizações em termos de locutor individual.

É claro, pode-se decidir que a categoria do ethos discursivo não se aplica à Internet, que deve ser reservada 
aos gêneros de discurso escritos ou orais. Mas isso seria uma atitude irrealista. Não só porque uma parte cada vez maior da comunicação é transmitida pela Internet, mas também porque o ethos é uma noção que, precisamente, é transversal aos vários modos de produção semiótica.

\subsection{Os iconotextos}

Independentemente da Internet, uma reflexão sobre o ethos também não pode ignorar a existência de iconotextos que associam intimamente texto e imagem com todos os problemas levantados pela hierarquização dos ethé. Consideremos, por exemplo, uma publicidade de uma agência de viagens publicada em uma revista (Le Monde Magazine, 26/03/2011, p.61, Figura 1) ${ }^{9}$. Capturamos a interação de vários ethé mostrados, situados em planos distintos; no mínimo, podemos distinguir:

- o ethos mostrado ligado a aspectos do verbal; mais especificamente, identificamos dois constituintes com ethé divergentes: o texto explicativo colocado na parte inferior e o slogan no topo do iconotexto;

- o ethos mostrado ligado à imagem, assim que se admite que há uma enunciação fotográfica (BASSO FOSSALI e DONDERO, 2011);

- o ethos mostrado no conjunto da publicidade, que associa os elementos verbais e icônicos para fazê-los convergir para uma instância enunciadora saliente, a marca, que torna proeminente a dimensão do ethos que chamamos de "experiencial".

Se o leitor está naturalmente inclinado a dar toda a sua importância ao ethos dito da ordem icônica, ao mundo ético de que participa a cena onde figura a personagem central, contemplativa, ele deve também levar em conta o ethos mostrado que surge da própria maneira em que a foto é apresentada e colocar esses dois elementos em relação com o ethos discursivo muito "prático" que emana do texto em uma faixa cinza. O ethos da marca se constrói pela integração dos vários planos de desdobramento do ethos.

Essa publicidade para Jet Tours separa claramente no iconotexto o verbal e o icônico. Mas esse não é necessariamente o caso. Na outra publicidade apresentada aqui (Grazia, 11-17/11/2011, p.11, Figura 2), há uma espécie de fusão entre os dois.

\footnotetext{
O texto na parte inferior da página é o seguinte:

"A NOVA OFERTA DE VIAGENS PERSONALIZADAS DE JET TOURS"

- A liberdade de construir a sua viagem ideal pelo melhor preço.

- Toda a experiência e a paixão de nossos consultores especialistas a serviço do seu projeto.

- As regiões mais bonitas do mundo para explorar: Ásia, Américas, Seychelles, Madagascar e Polinésia.

Remeta-nos o seu projeto no nosso site www.aucoeurdumonde.fr ou contacte um dos nossos especialistas pelo 0825700003 ou sua agência de viagens autorizada Jet Tours ou Thomas Cook."
}

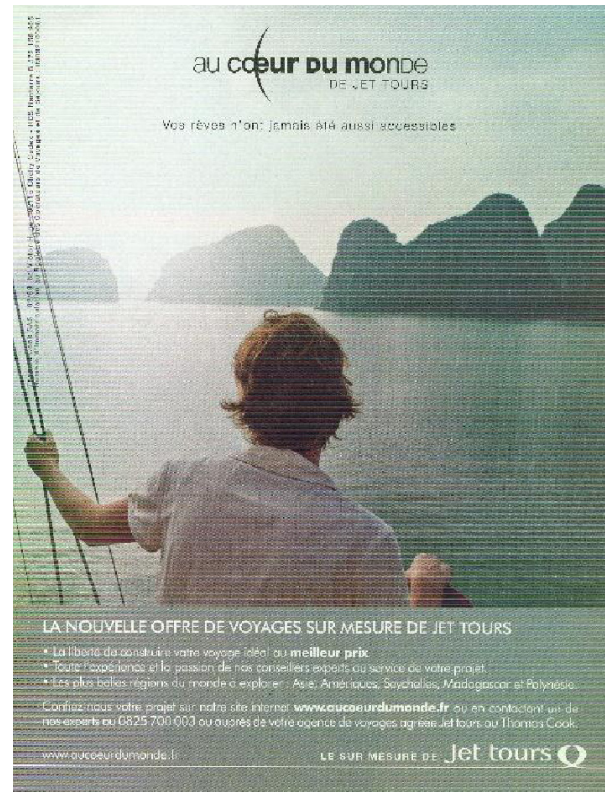

Figura 1. Jet Tours

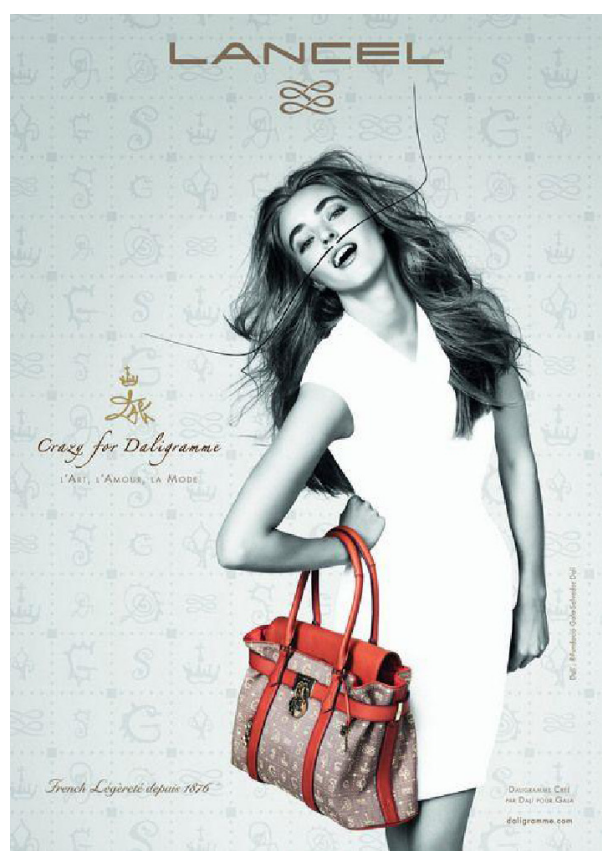

Figura 2. Lancel

O processo de incorporação em que é colocado o leitor dá primazia à dimensão experiencial do ethos, sublinhada pela personagem central, e à dimensão icônica. $\mathrm{O}$ enunciado colocado no canto inferior esquerdo ("French Légèreté desde 1876") está a serviço desse ethos experiencial, que ele categoriza como "leveza", uma noção que se aplica obviamente à enunciação desse iconotexto publicitário e a seu fiador, ou seja, a marca. Se na publicidade da Jet Tours havia divergência do ethos icônico e do ethos verbal, integrados a um nível superior, nessa publicidade da Lancel a convergência é total. 


\section{Conclusão}

Estudar o ethos é se basear em uma realidade simples, intuitiva, a de um fenômeno que é coextensivo a todo emprego da linguagem: o destinatário constrói necessariamente uma representação do locutor através do que ele diz e de sua maneira de dizer isso. Enquanto o ethos era um conceito puramente retórico, confinado ao domínio da arte oratória, um tipo de evidência a serviço de uma estratégia argumentativa unívoca, permanecemos pouco conscientes dos problemas que surgem de seu uso. Ao apropriar-se da noção de ethos a partir da década de 1980, estendendo seu campo de validade ao conjunto das produções discursivas, a análise do discurso passa a questionar seu conteúdo, seus poderes e seus limites. Mas parece-me que a reflexão ainda não foi longe o suficiente nesse sentido. $\mathrm{O}$ ethos continua sendo uma categoria insuficientemente especificada para ser a medida da diversidade de situações de comunicação. Ao distinguir três dimensões e colocá-las à prova de tipos de dados diferentes daqueles que habitualmente temos, espero ter contribuído para o enriquecimento de uma problemática cuja análise do discurso está longe de ter explorado todo o potencial.

\section{Referências}

AMOSSY, R. (Dir.). Images de soi dans le discours. La construction de l'éthos. Lausanne: Delachaux et Niestlé, 1999.

ARISTOTE. Rhétorique. Tradução M. Dufour. Paris: Les Belles-Lettres, 1967.
AUCHLIN, A. Éthos et expérience du discours: quelques remarques. In: WAUTHION, M.; SIMON, A. C. (Dir.). Politesse et idéologie. Rencontres de pragmatique et de rhétorique conversationnelle. Louvain: Peeters, 2001. p. 7-95.

BASSO FOSSALI, P. L.; DONDERO, M. G. Sémiotique de la photographie. Limoges: Presses Universitaires de Limoges, 2011.

DUCROT, O. Le dire et le dit. Paris: Minuit, 1984.

MAINGUENEAU, D. Genèses du discours. Liège: Mardaga, 1984.

MAINGUENEAU, D. Analyser les textes de communication. Paris: Dunod, 1998.

MAINGUENEAU, D. Lecture, incorporation et monde éthique. Études de linguistique appliquée, v. 119, p. 265-276, 2000.

MAINGUENEAU, D. Problèmes d'éthos. Pratiques, p. 55-68, 2002.

MAINGUENEAU, D. Retour critique sur l'éthos. Langage et société, v. 149, n. 3, p. 31-48, 2014.

RABATEL, A. L'effacement énonciatif dans les discours rapportés et ses effets pragmatiques. Langages, v. 156, p. 3-17, 2004.

RÉCANATI, F. Les énoncés performatifs. Contribution à la pragmatique. Paris: Minuit, 1981.

VION, R. "Effacement énonciatif" et stratégies discursives. In: DE MATTIA, M.; JOLY, A. (Dir.). De la syntaxe à la narratologie énonciative. Gap: Orphys, 2001. p. 331-354.

Recebido: 30/05/2018

Aprovado: 26/08/2018

(D) DOMINIQUE MAINGUENEAU < dominique.maingueneau@paris-sorbonne.fr> Professor e pesquisador da Sorbonne Université. 